\title{
Energy metabolism and autism: the ameliorative potential of carnosine and agmatine
}

\author{
Hipkiss AR* \\ Aston Research Centre for Healthy Ageing (ARCHA), School of Health and Life Sciences, Aston University, Birmingham, UK
}

\begin{abstract}
Recent studies have revealed that autistic spectrum disorders (ASD) is associated with enhanced glycolysis (i.e. establishment of the Warburg effect) accompanied by increased formation of glycated proteins in sera and urine. Both carnosine and agmatine levels in sera of autistic individuals are reported to be lower than in control subjects. Carnosine and agmatine can influence cellular energy metabolism, in part via effects on mTOR, thereby decreasing glycolysis and enhancing mitochondrial activity and thus countering onset of Warburg-like metabolism: other mechanisms including suppressing methylglyoxal toxicity are also discussed. Dietary supplementation studies with carnosine and arginine (agmatine precursor) indicate ameliorative activity towards behaviour in ASD subjects. It is suggested that co-administration of carnosine and agmatine should be explored as a potential route for ASD amelioration.
\end{abstract}

\section{Introduction}

A recent publication has suggested that autism spectrum disorders (ASD) is accompanied, associated and/or related to changes in energy metabolism, more specifically the imposition of enhanced aerobic glycolysis, coupled with a suppression of mitochondrial ATP synthesis, also known as the Warburg effect [1]. Another recent paper has revealed the presence of elevated amounts of oxidized, nitrated and glycated proteins in the plasma of some ASD subjects, as well as a disturbance in arginine metabolism and/or clearance [2]. The objective of the present piece is to attempt to integrate these findings by highlighting the possible ameliorative roles of carnosine and agmatine (decarboxylated arginine), both of which are diminished in sera of some ASD subjects [3-5].

\section{Energy metabolism and ASD}

The Vallée and Vallée hypothesis [1] proposes that ASD is strongly associated with "a shift in energy production from mitochondrial oxidative phosphorylation to aerobic glycolysis - despite the availability of oxygen" i.e. the imposition of the Warburg effect. Plausible mechanistic routes proposed include the $\mathrm{WNT} /$ beta-catenin pathway, and activation of the regulatory complex PI3Akt/mTOR [1].

It is uncertain whether the induction of the predominantly glycolytic metabolism is caused primarily by dysfunction of the PI3AktmTOR regulatory complex, provoked perhaps by glycated protein (also called advanced glycation end-products i.e. AGEs) [6] or whether the imposition of the Warburg-type metabolism is a response to some other causative event or events, such as mitochondrial dysfunction. Indeed, it has been claimed that ASD is associated with mitochondrial dysfunction [7-10], and a three-fold decline in oxidative phosphorylation has been detected in ASD subjects' granulocytes [10]. It would obviously be informative to determine if this deficit is systemic and also occurring in the CNS or exhibited solely in granulocytes.

There is evidence suggesting that formation and/or accumulation of propionic acid is associated with some cases of ASD [11-13], possibly originating in the gut tissue or more likely in the microbiome (mostly Clostridia bacterial species) [14]. It is thought that, in the brain, propionic acid inhibits GABA breakdown causing its accumulation [15] thereby affecting brain function. Interestingly, raised levels of $\beta$-alanine have been detected in the urine of some autistic subjects [4], whilst in other autistic individuals a decrease was detected [3]. These observations, although seemingly contradictory, may reflect differences in $\beta$-alanine generation and utilisation by the micro-organisms in the gut. $\beta$-Alanine is a precursor of pantothenic acid which, in turn, is a precursor of Co-enzyme-A ( $\mathrm{CoA}$ ) (synthesized by the gut microorganisms). The microbiome is the predominant source of pantothenic acid in the human body. One speculative suggestion is that propionic acid accumulates as a result of a failure in its carboxylation, which requires functional $\mathrm{CoA}$, hence propionic acid accumulates if synthesis of Co-A is compromised. General deficiency in CoA availability would also decrease fatty acid oxidation, as found in ASD [7,10,16-18]. The resultant mitochondrial dysfunction would have two important consequences which directly impact ASD. First, the decreased supply of electrons (i.e. acetyl units attached to $\mathrm{CoA}$ ) will provoke an increase in the generation of incompletely reduced oxygen molecules, i.e. oxygen free-radicals [19], the presence of which will provoke formation of deleterious reactive oxygen species (ROS) and reactive nitrogen species (RNS). Such a mechanism may account for the raised levels of protein oxidation and nitration recently detected in autistic patients' urine and plasma [2]. A second consequence of insufficient mitochondrial ATP synthesis may be a compensating upregulation of glycolysis in an attempt to maintain ATP levels [1]. Indeed enhanced glycolysis accompanied by mitochondrial abnormalities have been detected in ASD subjects (compared to siblings and controls) [20]. Importantly, upregulated glycolysis would enhance generation of the highly toxic bicarbonyl

${ }^{*}$ Correspondence to: Hipkiss AR, Aston Research Centre for Healthy Ageing (ARCHA), School of Health and Life Sciences, Aston University, Birmingham, B4 7ET, UK, E-mail: alanandjill@lineone.net

Key words: carnosine, agmatine, autism, glycolysis, glycation, mitochondria, methylglyoxal, propionic acid, rapamycin, $m T O R$

Received: May 16, 2018; Accepted: June 06, 2018; Published: June 11, 2018 
compound, methylglyoxal (MG), produced following spontaneous decomposition of the glycolytic intermediates, dihydroxyacetonephosphate and glyceraldehyde-3-phosphate. MG is a strong glycating agent and well-recognised as a major source of the post-synthetic protein modifications which characterise both type- 2 diabetes and ageing $[21,22]$. The notion that ASD is associated with enhanced MG generation is supported by the detection in some autistic subjects of gene polymorphisms in the MG detoxification enzyme, glyoxalase-1 [23-26], which could result in decreased MG elimination and increased macromolecular glycation. The increased glycolytic activity could therefore account for the raised levels of glycated proteins detected in autistic patients' plasma and urine [2], especially if glyoxalase-1 activity was insufficient to meet the increased generation of MG. However, it must be pointed out that the suggestion that ASD is associated with glyoxalase dysfunction has been disputed $[27,28]$. Never-the-less, it is interesting that (i) changes in glyoxalase-1 expression in white blood cells seems to influence mood in human subjects [29], and (ii) it has recently been reported that erythrocytes of autistic boys possess lower levels of the detoxification enzyme retinal dehydrogenase (RALDH1), than was present in controls [30], observations which suggest that detoxification deficiency may influence behaviour in ASD individuals. The possibility that autism is associated with aldehyde toxicity generally and acetaldehyde in particular, has been proposed [31]. Furthermore, it has recently been shown that MG readily reacts with $\beta$-alanine [32], a reaction which would decrease pantothenate synthesis and further compromise formation of the CoA in the microbiome, as outlined above. Additionally the microbiome can also generate a well-studied neurotoxin, 3-nitropropionic acid (3NPA), presumably from propionic acid, which can induce a range of neuropathologies in model animals [33], although no specific claims for ASD have been made. Biochemically, 3NPA inhibits the TCA cycle enzyme succinate dehydrogenase, thereby compromising mitochondrial ATP synthesis and so could induce a Warburg-like metabolic state. It is likely that any gut organism in which propionic acid accumulates (as discussed above) may also increase the potential for 3NPA generation following attack by reactive nitrogen species (RNS); it is noteworthy ASD sera is enriched with nitrated proteins [2]. Consequently, it is possible to integrate a number of observations associated with ASD, including mitochondrial dysfunction, propionic acid accumulation, increased urinary $\beta$-alanine levels, decreased pantothenate levels, decreased glyoxalase-1 activity, and raised levels of sera oxidized, nitrated and glycated proteins.

There is additional evidence that ASD may be associated directly with changes in energy metabolism. A number of studies showing that the anti-aging agent rapamycin, which suppresses mTOR signalling activity to decrease glycolysis and upregulate oxidative phosphorylation, also suppresses autism-like behaviour in animal models [34,35]. Glycated proteins (AGEs) have been shown to activate mTOR [6] and elevated mTOR activity was detected in cells obtained from ASD children [36,37], suggesting a possible causative relationship between these phenomena. Animals exposed to valproic acid have been used as an animal model of ASD [38]: amongst the resultant effects of valproic acid is a dose dependent stimulation of glycolysis [39] and, perhaps even more importantly, it has previously been observed that resveratrol, an anti-diabetic agent which inhibits nonenzymic glycosylation (glycation) of proteins [40], prevents valproic acid-induced social impairment in these animals [41]. Furthermore, ketogenic diets (presumably provoking very little glycolysis) have been shown to be somewhat effective in controlling ASD behavioural symptoms in human subjects [42]. Although it is uncertain whether these effects are mediated via the microbiome or specifically in the cells of CNS, these findings are nevertheless consistent with the suggestion that ASD is associated with increased protein glycation resulting from enhanced glycolysis and MG generation.

Deficiency in vitamin-D has also been proposed to play a role in ASD [43-45] and it has been claimed that vitamin D supplementation in children may improve symptoms of ASD [46]. It is interesting to note that vitamin $\mathrm{D}$ appears to play a role in controlling the reaction between advanced glycation end-products (AGEs) with their cellular receptors (RAGEs) [47-49], again observations consistent with the findings of elevated levels of protein glycation in ASD subjects.

\section{Carnosine and ASD}

The dipeptide carnosine ( $\beta$-alanyl-L-histidine), when given as a dietary supplement to autistic children, has been shown to exert beneficial effects on behaviour [50,51]. Furthermore, the levels of carnosine in urine [52] and sera [53] of autistic subjects are reported to be substantially lower (by up to 75\%) than in controls.

Although first described more than 100 years ago [54], carnosine was regarded as "enigmatic" [55]; its precise physiological function still remains uncertain. Amongst the variety of suggestions, all supported with evidence using model and/or cell and animal studies, carnosine can behave as a hydrogen ion buffer, anti-oxidant, anti-glycator, wound-healing agent, metal ion chelator, whilst beneficial effects towards diabetes, atherosclerosis, heart failure, tumour cell growth and cellular ageing have also been reported [56-58]. Interestingly, dietary supplementation studies in human subjects have revealed improvement in cognition and/or behaviour in schizophrenics [59], elderly subjects [60], Gulf War veterans [61] and as well as autistic children [3,53].

There are a number of possible mechanisms by which carnosine might ameliorate aspects of ASD. First, the additional presence of dietary dipeptide carnosine could, following its hydrolysis, provide a supply of $\beta$-alanine and thus allow pantothenate and CoA synthesis in the microbiome, and thereby permit effective oxidative phosphorylation and perhaps additionally ensuring removal of the propionic acid via its carboxylation using acetyl-CoA kinase. Secondly, as outlined above, in order to maintain ATP levels, a compensating response to mitochondrial dysfunction would be enhanced glycolysis, despite the presence of oxygen (i.e. Warburg effect). There is evidence that carnosine can partially suppress glycolysis and decrease glycolytic ATP synthesis in yeast [62] and in transformed cells [63-65], which may decrease synthesis of triose phosphates and MG formation. Carnosine can also directly react with methylglyoxal [66] and other reactive carbonyl compounds [67], as well as inhibit formation of glycated proteins as shown in whole animal studies [68,69] and in humans [70]. Carnosine has also been shown to exert regulatory effects on mitochondrial function $[71,72]$ as well as activate the Nrf2 transcription factor (regulator of the antioxidant response) and thereby enhance oxidative defence $[73,74]$. It is relevant to note that autism in young boys is associated with alteration in Nfr2 expression and/or function [75,76]. Furthermore, it should be noted that carnosine may mimic rapamycin to some degree in its ability to inhibit mTOR activity [77]; as noted above, rapamycin is a well-recognised mTOR inhibitor that exerts beneficial effects towards ASD subjects and in animal models $[35,36,78]$.

These properties (inhibitory effects on mTOR and glycolysis, suppression of MG-induced macromolecular modifications and enhancement of anti-oxidant defence) exhibited by carnosine 
would appear to counter the onset of the Warburg effect and might account for the beneficial effects of carnosine towards at least some aspects of ASD. Furthermore, carnosine has been shown to suppress acetaldehyde-mediated toxicity towards cultured cells [79] and DNAprotein cross-linking in a model system [66], observations consistent with the proposal that ASD is somehow associated with acetaldehydemediated dysfunction. It is interesting to note that carnosine seems to possess many of the properties which are likely to suppress generation of the changes exhibited by sera and urinary proteome detected in ASD subjects [2].

There is also a study showing that carnosine can ameliorate the deleterious effect of propionic acid in an animal model of ASD, although the mechanisms responsible have not been explored [80]. Recent studies have suggested that the DJ-1 protein complex can facilitate protein deglycation [32], including glycated $\beta$-alanine (induced by MG). Many years ago it was suggested that carnosine might participate the repair of glycated proteins (via deglycation and/or transglycation), perhaps acting as a recipient of the detached glycating agent [81]. However, the possibility that carnosine might participate in protein deglycation has not been explored experimentally.

Carnosine can also inhibit protein nitration by forming adducts such as NO-carnosine and carnosine nitrite [82]. Given that raised levels of protein nitration have been detected in ASD plasma and urine [2], as well as in hair and nails [83], this may partly explain carnosine's ability to moderate aspects ASD behaviour [50].

More recently it has been shown that romidepsin can ameliorate autism-like behavioural symptoms in a mouse model of ASD [84] by binding to zinc ions in the zinc pocket of histone deacetylase and thus altering gene expression. As carnosine is a well-known zinc chelator, one wonders if the dipeptide might also bind the zinc in histone deacetylase in a manner similar to romidepsin.

\section{Agmatine and ASD}

There is evidence from an animal study that agmatine (decarboxylated arginine) can be beneficial towards valproic acidinduced autism-like symptoms of ASD in an animal model [85] and that some ASD subjects possess decreased levels of agmatine in their sera [5]. While there is evidence that agmatine possesses antiinflammatory properties $[86,87]$, there is little direct evidence of any anti-glycation activity of agmatine, although the structure of the molecule (an amino group plus the guanidino group) resembles the strong but toxic anti-glycator, aminoguanidine. Consequently, it is suggested that agmatine should be very readily glycated by a variety of reactive aldehydes, including MG and acetaldehyde, although this property does not appear to have been investigated. Never-the-less it is very relevant to note that agmatine can bind ADP-ribose [88] which may indicate agmatine's possible inhibitory action towards protein modification by ADP-ribose, or its participation in reversible protein modification (e.g. NAD-dependent histone deacetylation or polyADP ribosylation). The fact that agmatine activity has been likened to that of the anti-aging agent rapamycin [89], including mTOR inhibition, suppression of glycolysis and activation of mitochondrial activity [90], supports this idea. The findings that ASD is associated with changes in arginine metabolism [35] and its intracellular distribution [2] reinforces the proposal that arginine's decarboxylation product, agmatine, might be ameliorative [91].

It is perhaps also interesting to note that agmatine can promote an increase in cyclic-AMP levels in tissues [90], but cyclic-AMP has been reported to suppress carnosine synthesis [92]. Such observations might suggest that while agmatine can suppress carnosine synthesis, but upon its glycation agmatine may not suppress carnosine synthesis, which could indicate a possible regulatory mechanism of carnosine production in response to endogenous and exogenous glycating agents. Agmatine has been shown to inhibit polyamine synthesis, but whether this property is suppressed following agmatine glycation has not been investigated. However, it has been proposed that polyamines generally can, by being readily glycated themselves [93], behave protectively and thereby prevent glycation of polypeptides and nucleic acids.

\section{Conclusions}

ASD causation is undoubtedly complex [94]; amongst the factors so far recognised are changes in the microbiome, enhanced glycolytic activity, mitochondrial dysfunction and alteration in redox activity, all of which, presumably together with unrecognised metabolic and exogenous agents, contribute to varying degrees to the changes in behaviour and social interaction which characterise autism. Amongst these factors are agents such as AGEs which affect energy metabolism directly or indirectly, especially glycolysis, oxidative phosphorylation and their potentially dysfunctional, glycated, by-products.

The proposal that ASD is associated with mTOR activation leading to enhanced glycolytic activity as exemplified by the establishment of the Warburg effect (as proposed by Vallée \& Vallée, [1]) is supported by the findings that not only is a ketogenic diet beneficial towards ASD [95], but that glycated proteins (i.e. AGEs) can indeed activate mTOR to provoke onset of the Warburg effect [6]. Thus carnosine and possibly agmatine, both being pluripotent and essentially non-toxic endogenous molecules which can decrease glycolysis, possibly via effects on mTOR $[77,89]$, plus their reactivity towards reactive carbonyls such as $M G$, may inhibit protein glycation and thereby ameliorate some of the consequences of increased glycolytic activity and exert beneficial effects on aspects of behaviour in ASD children. Although the specific mechanisms by which some of these effects are mediated may differ; for example control of protein nitration may occur via carnosine's direct reaction with the nitrating agent whereas agmatine may inhibit nitric oxide synthesis, such complementary mechanisms could conceivably be therapeutically efficacious. That changes in both carnosine and agmatine may be connected to ASD is also supported by the findings that their serum levels are substantially lower in ASD subjects and that they both can also ameliorate the effects of propionic acid, which is known to sometimes accumulate in ASD. It is also suggested that the ability of carnosine and agmatine to ameliorate the effects of $M G$, either directly or following upregulation of antioxidant defences may also contribute to their efficacy towards ASD. It is interesting to note that two of propionic acid's likely metabolites, 3-nitropropionate [96] and propionaldehyde [97], have also been associated with ASD; both carnosine and agmatine, could theoretically antagonise either their formation and/or toxicity via inhibiting propionate nitration or promoting aldehyde scavenging.

Whether combined treatment with both carnosine and agmatine is therapeutic towards ASD has not been explored. However, it has been noted that co-administration of carnosine and arginine (agmatine precursor) was more effective in combating hypoxic stress in rats than when either agent was supplied singly [98], an observation at least consistent with the above suggestion. More generally, as both carnosine and agmatine [99] when administered separately seem to exert beneficial effects towards aspects of both Parkinson's disease $[71,100,101]$ and Alzheimer's disease [102-104] in cellular and animal 
models, then perhaps their co-administration should be also explored towards these age-related neurodegenerative conditions.

\section{Conflicts of interest}

There are no conflicts of interest.

\section{References}

1. Vallée A, Vallée JN (2018) Warburg effect hypothesis in autism Spectrum disorders. Mol Brain 11: 1. [Crossref]

2. Anwar A, Abruzzo PM, Pasha S, Rajpoot K, Bolotta A, et al. (2018) Advanced glycation endproducts, dityrosine and arginine transporter dysfunction in autism - a source of biomarkers for clinical diagnosis. Mol Autism 9:3.

3. Zaki MM, Abdel-Al H, Al-Sawi M (2017) Assessment of plasma amino acid profile in autism using cation-exchange chromatography with postcolumn derivatization by ninhydrin. Turk J Med Sci 47: 260-267. [Crossref]

4. Mavel S, Nadal-Desbarats L, Blasco H, Bonnet-Brilhault F, Barthélémy C, et al. (2013) $1 \mathrm{H}-13 \mathrm{C}$ NMR-based urine metabolic profiling in autism spectrum disorders. Talanta 114: 95-102. [Crossref]

5. Esnafoglu E, Irende I (2018) Decreased plasma agmatine levels in autistic subjects. $J$ Neural Transm (Vienna) 125: 735-740. [Crossref]

6. Zhao X, Chen Y, Tan X, Zhang L, Zhang H, et al. (2018) Advanced glycation endproducts suppress autophagic flux in podocytes by activating mammalian target of rapamycin and inhibiting nuclear translocation of transcription factor EB. $J$ Pathol 245: 235-248. [Crossref]

7. Varga NÁ, Pentelényi K, Balicza P, Gézsi A, Reményi V, et al. (2018) Mitochondrial dysfunction and autism: comprehensive genetic analyses of children with autism and mtDNA deletion. Behav Brain Funct 14:4.

8. Hollis F, Kanellopoulos AK, Bagni C (2017) Mitochondrial dysfunction in Autism Spectrum Disorder: clinical features and perspectives. Curr Opin Neurobiol 45: 178187. [Crossref]

9. Pei L, Wallace DC (2017) Mitochondrial Etiology of Neuropsychiatric Disorders. Bio Psychiatry 83: 722-730. [Crossref]

10. Napoli E, Wong S, Hertz-Picciotto I, Giulivi C (2014) Deficits in bioenergetics and impaired immune response in granulocytes from children with autism. Pediatrics 133: e1405-1410. [Crossref]

11. de la Bâtie CD, Barbier V, Roda C, Brassier A, Arnoux JB, et al. (2017) Autism spectrum disorders in propionic acidemia patients. J Inherit Metab Dis. [Crossref]

12. Frye RE, Nankova B, Bhattacharyya S, Rose S, Bennuri SC, et al. (2017) Modulation of Immunological Pathways in Autistic and Neurotypical Lymphoblastoid Cell Lines by the Enteric Microbiome Metabolite Propionic Acid. Front Immunol 8:1670. [Crossref]

13. Choi J, Lee S, Won J, Jin Y, Hong Y, et al. (2018) Pathophysiological and neurobehavioral characteristics of a propionic acid-mediated autism-like rat model. PLoS One. 13: e0192925. [Crossref]

14. Macfabe D (2013) Autism: metabolism, mitochondria, and the microbiome. Glob $A d v$ Health Med 2: 52-66. [Crossref]

15. Morland C, Frøland AS, Pettersen MN, Storm-Mathisen J, Gundersen V, et al. (2018) Propionate enters GABAergic neurons, inhibits GABA transaminase, causes GABA accumulation and lethargy in a model of propionic acidemia. Biochem $J$ 475: 749-758 [Crossref]

16. Hollis F, Kanellopoulos AK, Bagni C (2017) Mitochondrial dysfunction in Autism Spectrum Disorder: clinical features and perspectives. Curr Opin Neurobiol 45: 178187. [Crossref]

17. Patowary A, Nesbitt R, Archer M, Bernier R, Brkanac Z (2017) Next Generation Sequencing Mitochondrial DNA analysis in Autism Spectral Disorder. Autism Res10: 1338-1343. [Crossref]

18. Xie Z, Jones A, Deeney JT, Hur SK, Bankaitis VA (2016) Inborn Errors of Long-Chain Fatty Acid Oxidation Link Neural Stem Cell Self-Renewal to Autism. Cell Rep 14: 991-999. [Crossref]

19. Powers SK (2014) Can antioxidants protect against disuse muscle atrophy? Sports Med 44 Suppl 2: S155-165. [Crossref]

20. Rose S, Bennuri SC, Wynne R (2017) Mitochondrial and redox abnormalities in autism lymphoblastoid cells: a sibling control study. FASEB J 31: 904-909. [Crossref]
21. Rabbani N, Xue M, Thornalley PJ (2016) Methylglyoxal-induced dicarbonyl stress in aging and disease: first steps towards glyoxalase 1-based treatments. Clin Sci (Lond) 130: 1677-1696. [Crossref]

22. Allaman I, Bélanger M, Magistretti PJ (2015) Methylglyoxal, the dark side of glycolysis. Front Neurosci 9: 23. [Crossref]

23. Gabriele S, Lombardi F, Sacco R, Napolioni V, Altieri L, et al. (2014) The GLO1 C332 (Ala111) allele confers autism vulnerability: family-based genetic association and functional correlates. J Psychiatr Res 59: 108-116. [Crossref]

24. Junaid MA, Kowal D, Barua M, Pullarkat PS, Sklower Brooks S, et al. (2004) Proteomic studies identified a single nucleotide polymorphism in glyoxalase I as autism susceptibility factor. Am J Med Genet A 131: 11-17. [Crossref]

25. Barua M, Jenkins EC, Chen W, Kuizon S, Pullarkat RK, et al. (2011) Glyoxalase I polymorphism rs 2736654 causing the Ala111Glu substitution modulates enzyme activity--implications for autism. Autism Res 4: 262-270. [Crossref]

26. Maher P (2012) Methylglyoxal, advanced glycation end products and autism: is there a connection? Med Hypotheses 78: 548-552. [Crossref]

27. Kovak J, Podkraj $\AA_{j}$ ek KT, Luk $\AA_{j} i$ Ä MM, Battelino T (2015) Weak association of glyoxalase 1 (GLO1) variants with autism spectrum disorder. Eur Child Adolesc Psychiatry 24: 75-82. [Crossref]

28. Wu YY, Chien WH, Huang YS, Gau SS, Chen CH (2008) Lack of evidence to support the glyoxalase 1 gene (GLO1) as a risk gene of autism in Han Chinese patients from Taiwan. Prog Neuropsychopharmacol Biol Psychiatry 32: 1740-1744. [Crossref]

29. Fujimoto M, Uchida S, Watanuki T, Wakabayashi Y, Otsuki K, et al. (2008) Reduced expression of glyoxalase-1 mRNA in mood disorder patients. Neurosci Lett 438: 196199. [Crossref]

30. Paval D, Rad F, Rusu , Niculae AÅž, Colosi HA, et al. (2017) Low Retina Dehydrogenase 1 (RALDH1) Level in Prepubertal Boys with Autism Spectrum Disorder: A Possible Link to Dopamine Dysfunction? Clin Psychopharmacol Neurosci 15: 229-236. [Crossref]

31. Jurnak F (2016) The Pivotal Role of Aldehyde Toxicity in Autism Spectrum Disorder The Therapeutic Potential of Micronutrient Supplementation. Nutr Metab Insights 14 57-77. [Crossref]

32. Matsuda N, Kimura M, Queliconi BB, Kojima W, Mishima M, et al. (2017) Parkinson's disease-related DJ-1 functions in thiol quality control against aldehyde attack in vitro. Sci Rep 7: 12816.

33. Liachenko S, Ramu J, Paule MG, Hanig J (2018) Comparison of quantitative T2 and $\mathrm{ADC}$ mapping in the assessment of 3-nitropropionic acid-induced neurotoxicity in rats Neurotoxicology 65: 52-59. [Crossref]

34. Winden KD, Ebrahimi-Fakhari D, Sahin M (2018) Abnormal mTOR Activation in Autism. Annu Rev Neurosci [Crossref]

35. Zhang J, Liu LM, Ni JF (2017) Rapamycin modulated brain-derived neurotrophic factor and B-cell lymphoma 2 to mitigate autism spectrum disorder in rats. Neuropsychiatr Dis Treat 13: 835-842. [Crossref]

36. Onore C, Yang H, Van de Water J, Ashwood P (2017) Dynamic Akt/mTOR Signaling in Children with Autism Spectrum Disorder. Front Pediatr 5: 43. [Crossref]

37. Nicolini C, Ahn Y, Michalski B, Rho JM, Fahnestock M. (2015) Decreased mTOR signaling pathway in human idiopathic autism and in rats exposed to valproic acid. Acto Neuropathol Commun 3:3. [Crossref]

38. Nicolini C, Fahnestock M (2018) The valproic acid-induced rodent model of autism Exp Neurol 299: 217-227. [Crossref]

39. Aucamp J, Van Dyk HC, Bronkhorst AJ, Pretorius PJ (2017) Valproic acid alter the content and function of the cell-free DNA released by hepatocellular carcinoma (HepG2) cells in vitro. Biochimie 140: 93-105. [Crossref]

40. Shen Y, Xu Z, Sheng Z (2017) Ability of resveratrol to inhibit advanced glycation end product formation and carbohydrate-hydrolyzing enzyme activity, and to conjugate methylglyoxal. Food Chem 216: 153-160. [Crossref]

41. Bambini-Junior V, Zanatta G, Della Flora Nunes G, Mueller de Melo G, Michels M, et al. (2014) Resveratrol prevents social deficits in animal model of autism induced by valproic acid. Neurosci Lett 583: 176-181. [Crossref]

42. El-Rashidy O, El-Baz F, El-Gendy Y, Khalaf R, Reda D, et al. (2017) Ketogenic die versus gluten free casein free diet in autistic children: a case-control study. Metab Brain Dis 32: 1935-1941. [Crossref] 
43. Berridge MJ (2018) Vitamin D deficiency: infertility and neurodevelopmental diseases (attention deficit hyperactivity disorder, autism, and schizophrenia). Am J Physiol Cell Physiol 314: C135-135C151. [Crossref]

44. El-Ansary A, Cannell JJ, Bjørklund G, Bhat RS, Al Dbass AM (2018) In the search for reliable biomarkers for the early diagnosis of autism spectrum disorder: the role of vitamin D. Metab Brain Dis 33: 917-931. [Crossref]

45. Guo M, Zhu J, Yang T, Lai X, Lei Y, et al. (2018) Vitamin A and vitamin D deficiencies exacerbate symptoms in children with autism spectrum disorders. Nutr Neurosci 16: 1-11. [Crossref]

46. Saad K, Abdel-Rahman AA, Elserogy YM, Al-Atram AA, El-Houfey AA, et al. (2018) Randomized controlled trial of vitamin D supplementation in children with autism spectrum disorder. J Child Psychol Psychiatry 59: 20-29. [Crossref]

47. Rüster C, Franke S, Reuter S, Mrowka R, Bondeva T, Wolf G (2016) Vitamin D3 Partly Antagonizes Advanced-Glycation Endproducts-Induced NF?B Activation in Mouse Podocytes. Nephron 134: 105-116. [Crossref]

48. Merhi Z, Buyuk E, Cipolla MJ (2018) Advanced glycation end products alter steroidogenic gene expression by granulosa cells: an effect partially reversible by vitamin D. Mol Hum Reprod 24: 318-326.

49. Molinuevo MS, Fernández JM, Cortizo AM, McCarthy AD, Schurman L, et al. (2017) Advanced glycation end products and strontium ranelate promote osteogenic differentiation of vascular smooth muscle cells in vitro: Preventive role of vitamin D. Mol Cell Endocrinol 450: 94-104. [Crossref]

50. Chez MG, Buchanan CP, Aimonovitch MC, Becker M, Schaefer K, et al. (2002) Double-blind, placebo-controlled study of L-carnosine supplementation in children with autistic spectrum disorders. J Child Neurol 17: 833-837. [Crossref]

51. Hajizadeh-Zaker R, Ghajar A, Mesgarpour B, Afarideh M, Mohammadi MR, et al. (2018) L-Carnosine as an Adjunctive Therapy to Risperidone in Children with Autistic Disorder: A Randomized, Double-Blind, Placebo-Controlled Trial. J Child Adoles Psychopharmacol 28: 74-81. [Crossref]

52. Ming X, Stein TP, Barnes V, Rhodes N, Guo L (2012) Metabolic perturbance in autism spectrum disorders: a metabolomics study. J Proteome Res 11: 5856-5862. [Crossref]

53. Bala KA, DoÄŸan M, Mutluer T, Kaba S, Aslan O, et al. (2016) Plasma amino acid profile in autism spectrum disorder (ASD). Eur Rev Med Pharmacol Sci 20: 923-929. [Crossref]

54. Boldyrev AA (2000) Problems and perspectives in studying the biological role of carnosine. Biochemistry (Mosc) 65: 751-756. [Crossref]

55. Bauer K (2005) Carnosine and homocarnosine, the forgotten, enigmatic peptides of the brain. Neurochem Res 30: 1339-1345. [Crossref]

56. Boldyrev AA, Aldini G, Derave W (2013) Physiology and pathophysiology of carnosine. Physiol Rev 93: 1803-1845. [Crossref]

57. Hipkiss AR, Baye E, de Courten B (2016) Carnosine and the processes of ageing. Maturitas 93: 28-33. [Crossref]

58. Cararo JH, Streck EL, Schuck PF, Ferreira Gda C (2015) Carnosine and Related Peptides: Therapeutic Potential in Age-Related Disorders. Aging Dis 6: 369-379. [Crossref]

59. Chengappa KN, Turkin SR, DeSanti S, Bowie CR, Brar JS, et al. (2012) A preliminary, randomized, double-blind, placebo-controlled trial of L-carnosine to improve cognition in schizophrenia. Schizophr Res 142: 145-152. [Crossref]

60. Szczesniak D, BudzeÅ S, KopeÄ W, Rymaszewska J (2014) Anserine and carnosine supplementation in the elderly: Effects on cognitive functioning and physical capacity. Arch Gerontol Geriatr 59: 485-490. [Crossref]

61. Baraniuk JN, El-Amin S, Corey R, Rayhan R, Timbol C (2013) Carnosine treatment for gulf war illness: a randomized controlled trial. Glob J Health Sci 5: 69-81. [Crossref]

62. Cartwright SP, Bill RM, Hipkiss AR (2012) L-carnosine affects the growth of Saccharomyces cerevisiae in a metabolism-dependent manner. PLoS One. 7: e45006.

63. Holliday R, McFarland GA (1996) Inhibition of the growth of transformed and neoplastic cells by the dipeptide carnosine. Br J Cancer 73: 966-971. [Crossref]

64. Renner C, Asperger A, Seyffarth A, Meixensberger J, Gebhardt R, et al. (2010a) Carnosine inhibits ATP production in cells from malignant glioma. Neurol Res 32: 101-105. [Crossref]

65. Renner C, Zemitzsch N, Fuchs B, Geiger KD, Hermes M, et al. (2010b) Carnosine retards tumor growth in vivo in an NIH3T3-HER2/neu mouse model. Mol Cancer 9:2. [Crossref]
66. Hipkiss AR, Preston JE, Himsworth DT, Worthington VC, Keown M, et al. (1998) Pluripotent protective effects of carnosine, a naturally occurring dipeptide. Ann N Y Acad Sci 854: 37-53. [Crossref]

67. Vistoli G, Colzani M, Mazzolari A, Gilardoni E, Rivaletto C, et al. (2017) Quenching activity of carnosine derivatives towards reactive carbonyl species: Focus on a-(methylglyoxal) and ß-(malondialdehyde) dicarbonyls. Biochem Biophys Res Commun 492: 487-492. [Crossref]

68. Aydin AF, Küçükgergin C, Çoban J, Dogan-Ekici I, Dogru-Abbasoglu S, (2018). arnosine prevents testicular oxidative stress and advanced glycation end product formation in D-galactose-induced aged rats. Andrologia. 50.

69. Bingul, YÄlmaz Z, Aydan AF1, Ãoban J, DoÄŸru-AbbasoÄŸlu S1, et al. (2017) Antiglycation and anti-oxidant efficiency of carnosine in the plasma and liver of aged rats. Geriatr Gerontol Int 17: 2610-2614. [Crossref]

70. Houjeghani S, Kheirouri S, Faraji E, Jafarabadi MA (2018) L-Carnosine supplementation attenuated fasting glucose, triglycerides, advanced glycation end products, and tumor necrosis factor-a levels in patients with type 2 diabetes: a doubleblind placebo-controlled randomized clinical trial. Nutr Res 49: 96-106. [Crossref]

71. Zhao J, Shi L, Zhang LR (2017) Neuroprotective effect of carnosine against salsolinolinduced Parkinson's disease. Exp Ther Med 14: 664-670. [Crossref]

72. Baek SH, Noh AR, Kim KA, Akram M, Shin YJ, et al. (2014) Modulation of mitochondrial function and autophagy mediates carnosine neuroprotection against ischemic brain damage. Stroke 45: 2438-2443. [Crossref]

73. Ooi TC, Chan KM, Sharif R (2017) Zinc L-carnosine suppresses inflammatory responses in lipopolysaccharide-induced RAW 264.7 murine macrophages cell line via activation of $\mathrm{Nrf} 2 / \mathrm{HO}-1$ signaling pathway. Immunopharmacol Immunotoxicol 39: 259-267. [Crossref]

74. Ahshin-Majd S, Zamani S, Kiamari T, Kiasalari Z, Baluchnejadmojarad T, et al (2016) Carnosine ameliorates cognitive deficits in streptozotocin-induced diabetic rats: Possible involved mechanisms. Peptides 86: 102-111. [Crossref]

75. Stamova BS, Tian Y, Nordahl CW, Shen MD, Rogers S, et al. (2013) Evidence for differential alternative splicing in blood of young boys with autism spectrum disorders. Mol Autism 4: 30. [Crossref]

76. Napoli E, Song G, Wong S, Hagerman R (2016) Altered Bioenergetics in Primary Dermal Fibroblasts from Adult Carriers of the FMR1 Premutation Before the Onset of the Neurodegenerative Disease Fragile X-Associated Tremor/Ataxia Syndrome. Cerebellum 15: 552-564. [Crossref]

77. Zhang Z, Miao L, Wu X, Liu G, Peng Y, et al. (2014) Carnosine Inhibits the Proliferation of Human Gastric Carcinoma Cells by Retarding Akt/mTOR/p70S6K Signaling. J Cancer 5: 382-389. [Crossref]

78. Winden KD, Ebrahimi-Fakhari D, Sahin M (2018) Abnormal mTOR Activation in Autism. Annu Rev Neurosci [Crossref]

79. Hipkiss AR, Michaelis J, Syrris P, Dreimanis M (1995) Strategies for the extension of human lifespan. Perspect. in Human Biol 1: 59-70.

80. El-Ansary A, Shaker GH, El-Gezeery AR, Al-Ayadhi L (2013) The neurotoxic effect of clindamycin - induced gut bacterial imbalance and orally administered propionic acid on DNA damage assessed by the comet assay: protective potency of carnosine and carnitine. Gut Pathog 5: 9. [Crossref]

81. Szwergold BS (2005) Intrinsic toxicity of glucose, due to non-enzymatic glycation, is controlled in-vivo by deglycation systems including: FN3K-mediated deglycation of fructosamines and transglycation of aldosamines. Med Hypotheses 65: 337-348. [Crossref]

82. Fontana M, Pinnen F, Lucente G, Pecci L (2002) Prevention of peroxynitrite-dependent damage by carnosine and related sulphonamido pseudodipeptides. Cell Mol Life Sci 59: 546-551. [Crossref]

83. Lakshmi Priya MD, Geetha A (2011) A biochemical study on the level of proteins and their percentage of nitration in the hair and nail of autistic children. Clin Chim Acto 412: 1036-1042. [Crossref]

84. Qin L, Ma K, Wang ZJ, Hu Z, Matas E, et al. (2018) Social deficits in Shank3-deficient mouse models of autism are rescued by histone deacetylase (HDAC) inhibition. Nat Neurosci 21: 564-575. [Crossref]

85. Kim JW, Seung H, Kim KC, Gonzales ELT, Oh HA, et al. (2017) Agmatine rescues autistic behaviors in the valproic acid-induced animal model of autism. Neuropharmacology 113: 71-81. [Crossref] 
86. Turan I, Ozacmak HS, Ozacmak VH, Barut F, AraslÄ M (2017) Agmatine attenuates intestinal ischemia and reperfusion injury by reducing oxidative stress and inflammatory reaction in rats. Life Sci 189: 23-28. [Crossref]

87. Kim JM, Lee JE, Cheon SY, Lee JH, Kim SY, et al. (2016) The Anti-inflammatory Effects of Agmatine on Transient Focal Cerebral Ischemia in Diabetic Rats. $J$ Neurosurg Anesthesiol 28: 203-213. [Crossref]

88. Laing S, Unger M, Koch-Nolte F, Haag F (2011) ADP-ribosylation of arginine. Amino Acids 41: 257-269. [Crossref]

89. Neis VB, Moretti M, Bettio LE, Ribeiro CM, Rosa PB, et al. (2016) Agmatine produces antidepressant-like effects by activating AMPA receptors and mTOR signaling. Eur Neuropsychopharmacol 26: 959-971. [Crossref]

90. Nissim I, Horyn O, Daikhin Y, Chen P, Li C, et al. (2014) The molecular and metabolic influence of long term agmatine consumption. J Biol Chem 289: 9710-9729. [Crossref]

91. Gilad GM, Gilad VH (2013) Evidence for oral agmatine sulfate safety--a 95-day high dosage pilot study with rats. Food Chem Toxicol 62: 758-762. [Crossref]

92. Schulz M, Hamprecht B, Kleinkauf H, Bauer K (1989) Regulation by dibutyryl cyclic AMP of carnosine synthesis in astroglia-rich primary cultures kept in serum-free medium. J Neurochem 52: 229-234. [Crossref]

93. Gugliucci A, Menini T (2003) The polyamines spermine and spermidine protect proteins from structural and functional damage by AGE precursors: a new role for old molecules? Life Sci 72: 2603-2616. [Crossref]

94. Ji X, Kember RL, Brown CD, BuÄan M, et al. (2016) Increased burden of deleterious variants in essential genes in autism spectrum disorder. Proc Natl Acad Sci U S A 113: 15054-15059. [Crossref]

95. Newell C, Bomhof MR, Reimer RA, Hittel DS, Rho JM, et al. (2016) Ketogenic diet modifies the gut microbiota in a murine model of autism spectrum disorder. Mol Autism 7: 37. [Crossref]
96. Alarcón-Herrera N, Flores-Maya S, Bellido B, García-Bores AM, Mendoza E, et al. (2017) Protective effects of chlorogenic acid in 3-nitropropionic acid induced toxicity and genotoxicity. Food Chem Toxicol 109: 1018-1025. [Crossref]

97. Kalkbrenner AE, Windham GC, Zheng C, McConnell R, Lee NL, et al. (2018) Air Toxics in Relation to Autism Diagnosis, Phenotype, and Severity in a U.S. FamilyBased Study. Environ Health Perspect 126: 037004. [Crossref]

98. Fadda LM, Attia HA, Al-Rasheed NM, Ali HM, et al. (2017) Attenuation of DNA damage and mRNA gene expression in hypoxic rats using natural antioxidants. $J$ Biochem Mol Toxicol 31. [Crossref]

99. Laube G, Bernstein HG (2017) Agmatine: multifunctional arginine metabolite and magic bullet in clinical neuroscience? Biochem J 474: 2619-2640. [Crossref]

100. Hipkiss AR (2018) Glycotoxins: Dietary and Metabolic Origins; Possible Amelioration of Neurotoxicity by Carnosine, with Special Reference to Parkinson's Disease. Neurotox Res [Crossref]

101. Tsai SJ, Kuo WW, Liu WH, Yin MC (2010) Antioxidative and anti-inflammatory protection from carnosine in the striatum of MPTP-treated mice. J Agric Food Chem 58: 11510-11516. [Crossref]

102. Kawahara M, Tanaka KI, Kato-Negishi M (2018) Zinc, Carnosine, and Neurodegenerative Diseases. Nutrients 10. [Crossref]

103. Herculano B, Tamura M, Ohba A, Shimatani M, Kutsuna N, et al. (2013) B-alanylL-histidine rescues cognitive deficits caused by feeding a high fat diet in a transgenic mouse model of Alzheimer's disease. J Alzheimers Dis 33: 983-987. [Crossref]

104. Hipkiss AR (2007) Could carnosine or related structures suppress Alzheimer's disease? J Alzheimers Dis 11: 229-240. [Crossref]

Copyright: $₫ 2018$ Hipkiss AR. This is an open-access article distributed under the terms of the Creative Commons Attribution License, which permits unrestricted use, distribution, and reproduction in any medium, provided the original author and source are credited. 